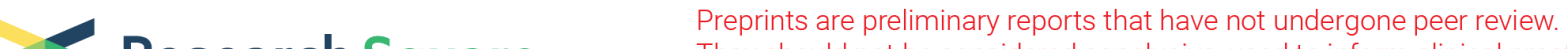 Research Square They should not be considered conclusive, used to inform clinical practice, or referenced by the media as validated information.
}

\section{Peripheral oxygen measurements in suspected elderly COVID-19 patients can be an effective tool for alerting physicians}

Carmino A De Souza ( $\sim$ carmino@unicamp.br)

Medical Sciences Faculty of University of Campinas https://orcid.org/0000-0001-8656-8374

Eliana C M Miranda

Data Center and Statistics of University of Campinas https://orcid.org/0000-0002-7177-7664

Deise Hadich

Health Department of Campinas City Hall

Monica Nunes

Health Department of Campinas City Hall

Debora Masetto

Health Department of Campinas City Hall

Daiane C P Morato

Health Department of Campinas City Hall

\section{Raquel Scandiuzzi}

Health Department of Campinas City Hall

Maria do Carmo Ferreira

Health Department of Campinas City Hall

Lair Zambon

Medical Sciences Faculty, University of Campinas https://orcid.org/0000-0002-3722-1697

Andrea von Zuben

Health Vigilance Department of Campinas City Hall

\section{Research Article}

Keywords: Asymptomatic Hypoxia, SARS-CoV2, COVID-19, Primary Health System

Posted Date: April 27th, 2021

DOl: https://doi.org/10.21203/rs.3.rs-454833/v1

License: (c) (1) This work is licensed under a Creative Commons Attribution 4.0 International License.

Read Full License 


\section{Abstract}

Since December 2019 the world has been facing a newly identified coronavirus named SarsCov-2 which is the causative agent of COVID-19 that produces different symptoms. One of these symptoms is asymptomatic hypoxia, particularly in elderly patients. Despite the absence of signs of respiratory distress, many patients evolve to respiratory failure. The cause of this asymptomatic hypoxia remains unclear; therefore our goal was to evaluate the utility of peripheral oxygen measurements using oximetry in elderly patients with suspected COVID-19 and with no apparent signs of shortness of breath, during 10 consecutive days. Every elderly patient with suspected COVID-19 who sought medical care at one of the 12 Primary Health Unit (PHU) in the South-West area of Campinas, Sao Paulo State was enrolled in the 10-days monitoring report. Each patient had the levels of oxygen saturation $\left(\mathrm{SpO}_{2}\right)$ monitored by pulse oximeter from the fifth to the tenth days after the onset of symptoms and, when possible, twice a day; 1297 patients (pts) were followed during the period from August 2020 to February 2021. A total of 9023 measurements were carried out using a $\mathrm{SpO}_{2}$ pulse oximeter. $163(12.5 \%)$ cases were referred to the Emergency Room and 37 (3\%) had to be hospitalized. The highest frequencies of symptoms occurred during the $6^{\text {th }}$ and $8^{\text {th }}$ day and included cough (16.8\%), fatigue $(12.8 \%)$, headache $(9.7 \%)$, loss of taste and/or smell (6.8\%). Among the patients who were hospitalized, 13 died (1\%). The asymptomatic hypoxia remains unclear; however, the measurement of $\mathrm{SpO}_{2}$ levels appears to be a cheap and effective tool to be used as an alert system for further evaluation.

\section{Introduction}

At the end of 2019 a newly identified coronavirus named SarsCov-2 which is the causative agent of COVID-19 (coronavirus disease 2019) emerged in Wuhan, China, resulting in a Pandemic that has affected countries all over the world ${ }^{1}$. This disease produces different symptoms including fever, cough, headache, loss of taste, smell or appetite, shortness of breath, amongst others. One of the most important symptoms is shortness of breath due to hypoxia ${ }^{2}$.

Hypoxia refers to low levels of oxygen saturation $\left(\mathrm{SpO}_{2}\right)$ in the body tissues (less than $90 \%$ ) whereas hypoxemia is defined as a decrease in the partial pressure of $\mathrm{SpO}_{2}$ levels in the blood. Hypoxia can be easily diagnosed by monitoring $\mathrm{SpO}_{2}$ with a pulse oximeter and hypoxemia is determined by a blood gas sample taken from an artery, demanding more material, time and a health technician. Therefore, a hypoxia exam appears to be a simpler and cheaper method. "Silent" hypoxia is a condition in which the patient does not complain of dyspnea or signs of respiratory distress but presents a $\mathrm{SpO}_{2}$ of less than $94 \%$.

Recently, some studies have suggested asymptomatic hypoxia in COVID-19 as being associated with poor outcomes ${ }^{3,4}$. Furthermore, epidemiological studies have also called attention to advanced age as risk factor to COVID-195. Therefore, our goal was to evaluate the utility of peripheral oxygen 
measurements using oximetry in elderly patients (pts) with suspected COVID-19 but with no shortness of breath.

\section{Methods}

The population of the city of Campinas in the Sao Paulo State, Brazil, is 1,200,000 inhabitants. The Health Public System of Campinas City Hall established a weekly monitoring report of asymptomatic elderly pts with suspected COVID-19 using oximetry during six consecutive days after the onset of symptoms, in the South-West area of Campinas which has 12 Primary Health Units, during the period from August 2020 to February 2021. Silent hypoxia was considered as a $\mathrm{SpO}_{2}$ level between $90 \%$ and $94 \%$, whereas hypoxia $<90 \%$. Statistical analyses was carried out applying $\chi^{2}$ tests to compare categorical data, and SPSS v. 24 was used considering P-value $<5 \%$ significant.

A total of 1297 elderly ( $\geq 60$ years old) patients (pts) were followed up during six consecutive days from August 2020 to February 2021. A total of 9023 measurements were carried out using $\mathrm{SpO}_{2}$ with a pulse oximeter; $4519(50.1 \%)$ in the morning and $4504(49.9 \%)$ in the afternoon. $163(12.5 \%)$ cases were referred to the Emergency Room and 37 (3\%) had to be hospitalized. Among the patients who were hospitalized, 13 died (1\%).

During some days, 1069 pts had at least $\mathrm{SpO}_{2}$ measurements carried out twice a day (in the morning and afternoon), the measurements were grouped and compared to attain the highest measurement by period (Table 1). The highest measurements occurred during the morning after the $5^{\text {th }}$ day; in $2533(72.5 \%)$ during the morning vs. $961(27.5 \%)$ during the afternoon ( $p=0.01)$. Nevertheless when this data was analyzed considering categorized saturation values, no difference was detected (Table 2).

The highest frequencies of symptoms occurred during the $6^{\text {th }}$ and $8^{\text {th }}$ day and comprised: cough (16.8\%), fatigue (12.8\%), headache (9.7\%), loss of taste and/or smell (6.8\%), diarrhea (3.6\%) and fever $(2.5 \%)$, Table 3.

\section{Discussion}

Clearly, dyspnea in patients with COVID-19, was associated to poor a outcome ${ }^{3}$ nevertheless, as indicated by the $C D C^{6}$ and other health policies all over the world"dyspnea is not a key criterion of initial severity in patients with COVID-19, and patients with a mild clinical presentation may not initially require hospitalization." Couzin-Frankel ${ }^{7}$ raised an interesting debate regarding the treatment of patients with low blood oxygen levels however with no trouble breathing, highlighting that dyspnea is the sensation of shortness of breath, whereas hypoxia is low oxygen levels in the blood. This silent hypoxia requires further investigation, beyond laboratorial tests, to understand the reason some COVID-19 patients are able to continue with their normal daily activities despite hypoxia ${ }^{3}$. A satisfactory hypothesis is that silent 
hypoxia is the result of the differential effect of $\mathrm{O}_{2}$ and $\mathrm{CO}_{2}$ during gas exchange that could produce a relative preservation of the lungs' ability to excrete $\mathrm{CO}_{2}$ despite the falling $\mathrm{O}_{2}$ levels ${ }^{8}$.

In summary, peripheral oxygen measurements using oximetry in this elderly group achieved excellent results, with only a $3 \%$ of hospitalization and $1 \%$ of deaths. It is necessary to underline that all measurements were carried out by specialized healthcare professionals in the primary health units, and not only were $\mathrm{SpO}_{2}$ measurements carried out, but also the overall exams to guarantee the general wellbeing of the patient. Self-monitoring of pulse oximetry by patients themselves can represent a problem, mainly due to the challenge of adequate calibration data, producing less accurate results ${ }^{9}$.

\section{Conclusion}

The utility of $\mathrm{SpO}_{2}$ measurements by a health care professional can be a valuable tool to be used as an alert system for further evaluation. These results could have an important impact on the monitoring and assistance protocols for patients affected by Covid-19 in the primary health network, aiding in the active surveillance and early identification of patients with a drop in $\mathrm{O}_{2}$ saturation. This tool could be useful to predict outcomes.

\section{Declarations}

Acknowledgments: We would like to thank the support of the Health Secretary from Campinas City Hall, SP, Brazil and all participating patients and families.

\section{Author contributions statement}

CDS, DH and AvZ designed, collected and analyzed the data, wrote and reviewed the manuscript; ECMM performed the statistical analysis, wrote and reviewed the manuscript. MN, DM, DCPM RS, MCF and LZ contributed substantially to the clinical protocol, training of health communitarian agents, the inclusion and control of patient outcomes. All authors performed a critical revision of the manuscript and approved the final draft.

Competing interests statement: none declared.

Patient consent for publication: None required.

Funding: The authors have no specific grant to declare for this research from any funding agency in the public, commercial or not-for-profit sectors.

Availability of data and material: All de-identified data are available upon request.

Ethics approval and consent to participate: All procedures explained in the manuscript were in accordance with the ethical standards of the university of the social welfare and rehabilitation research 
committee, and with the 1964 Helsinki Declaration. All information anonymously collected and received participants' contest.

\section{References}

1. Sebastiaan Dhont, Eric Derom Eva Van Braeckel, Pieter Depuydt, Bart N Lambrech. The pathophysiology of 'happy' hypoxemia in COVID-19. Dhontet al. Respiratory Research (2020) 21:198.

2. Harun, MA, Hossain, MM, Bari, MA, et al. Pulse Oximetry is Essential in Home Management of Elderly COVID-19 Patients. Bangladesh Journal of Otorhinolaryngology (2020) 26:55-67.

3. Brouqui P, Amrane S, Million M, et al. Asymptomatic hypoxia in COVID-19 is associated with poor outcome. International Journal of Infectious Diseases (2021) 102:233-238.

4. Wilkerson RG, Adler JD, Shah NG, et al. Silent hypoxia: A harbinger of clinical deterioration in patients with COVID-19. American Journal of Emergency Medicine (2020) 38:2243.e5-2243.e6

5. Vitiello A, La Porta R, Ferrara F. Correlation between the use of statins and COVID-19: what do we know? BMJ Evidence-Based Medicine (2020) December 2. doi:10.1136/bmjebm-2020-111589

6. Anon. Interim Clinical Guidance for Management of Patients with Confirmed Coronavirus Disease (COVID-19): Clinical Management and Treatment. 2020. https://wwwcdcgov/coronavirus/2019ncov/hcp/clinical-guidance-management-patientshtml\#clinical-management-treatment\%3C.

7. Couzin-Frankel J. The mystery of the pandemic's'happy hypoxia'. Science. 2020; 368(6490): 455-6. https://doi.org/10.1126/science.368.6490.455.

8. Mortaz E, Malkmohammad M, Jamaati H, et. Al. Silent hypoxia: higher NO in red blood cells of COVID-19 patients. BMC Pulmonary Medicine (2020)20:269.

9. Tobin MJ, Laghi F, and Jubran A. Why COVID-19 silent hypoxemia is baffling to Physicians. Am J Respir Crit Care Med 2020 Aug 1, 202:3- 356-360.

\section{Tables}

Table 1. The highest $\mathrm{SpO}_{2}$ measurement by period 


\begin{tabular}{|c|c|c|c|}
\hline Measuring Days & $\begin{array}{l}\text { Morning } \\
\mathrm{n}(\%)\end{array}$ & $\begin{array}{l}\text { Afternoon } \\
\mathrm{n}(\%)\end{array}$ & P-value \\
\hline $5^{\text {th }}$ & $227(9)$ & $123(12.8)$ & 0.016 \\
\hline $6^{\text {th }}$ & $381(15)$ & $140(14.6)$ & \\
\hline $7^{\text {th }}$ & $441(18)$ & 167 (17.3) & \\
\hline $8^{\text {th }}$ & 491 (19) & $169(17.6)$ & \\
\hline $9^{\text {th }}$ & $496(19.5)$ & $196(20.5)$ & \\
\hline $10^{\text {th }}$ & 497 (19.5) & $166(17.2)$ & \\
\hline Total & $2533(100)$ & $961(100)$ & 3494 \\
\hline
\end{tabular}

Table 2. $\mathrm{SpO}_{2}$ measurements by period of 1069 pts

\begin{tabular}{|c|c|c|c|}
\hline $\mathrm{SpO}_{2}$ values & Morning & Afternoon & $P$ \\
\hline$\geq 95 \%$ & 3130 (89.5) & 3161 (90.5) & \multirow[t]{3}{*}{0.23} \\
\hline $94-90 \%$ & $347(10.0)$ & $322(9.2)$ & \\
\hline$<90 \%$ & $17(0.5)$ & $10(0.3)$ & \\
\hline Total & 3494 & 3494 & - \\
\hline
\end{tabular}

Table 3. Distribution of symptoms between $5^{\text {th }}$ and $10^{\text {th }}$ day of $\mathrm{SpO}_{2}$ measurements

\begin{tabular}{|lllllll|}
\hline Symptoms\day & $5^{\text {th }}$ & $6^{\text {th }}$ & $7^{\text {th }}$ & $8^{\text {th }}$ & $9^{\text {th }}$ & $10^{\text {th }}$ \\
\hline Fever & 23 & 24 & $\mathbf{3 2}$ & 27 & 24 & 15 \\
\hline Cough & 192 & $\mathbf{2 1 8}$ & 199 & 201 & 209 & 171 \\
\hline Headache & 102 & 114 & $\mathbf{1 2 6}$ & 114 & 110 & 77 \\
Fatigue & 122 & 135 & 167 & 151 & 147 & 139 \\
Diarrhea & 37 & 47 & 41 & 37 & 43 & 34 \\
\hline Loss of taste/smell & 66 & 79 & 88 & $\mathbf{8 9}$ & 85 & 78 \\
\hline
\end{tabular}

